\title{
Guest Editor's Overview
}

T THE 1999 International Microwave Symposium, held in Anaheim, CA, resulted in the submission of 127 expanded papers for consideration for this Special Symposium Issue of the IEEE TRANSACTIONS ON MicRowAVE THEORY AND TECHNIQUES. From this group, 59 papers (46\%) were accepted. One accepted paper was withdrawn, leaving 58 papers. Of these, $72 \%$ are from authors outside the U.S. The microwave field is truly international. The papers span a wide range, and are grouped in the following categories: Systems, Photonics, Filters, Computer-Aided Design (CAD), Circuits, and Measurements.

This Special Issue includes reports from the Symposium Chair, Robert L. Eisenhart, and the Technical Program Committee Chair, H. J. Kuno. In addition, Peter W. Staecker contributed a report on this year's awards. There are two

Publisher Item Identifier S 0018-9480(99)08404-5. invited papers. John R. Forrest has written a paper based on his excellent plenary speech at the symposium. This year's Pioneer Award winners, Robert L. Eisenhart and Peter J. Khan, have also contributed a retrospective paper on their work.

I thank the authors for their contributions, and I regret that more papers could not be included. I appreciate the thoughtful work of the many reviewers. At Caltech, Carol Sosnowski made several large complicated mailings on a very tight schedule.

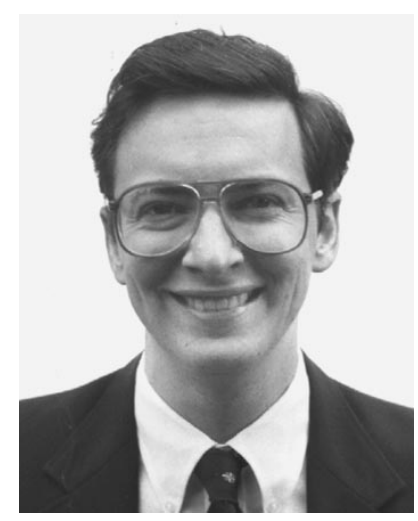

David B. Rutledge (S'77-M'77-SM'89-F'93) received the B.S. degree in mathematics from Williams College, Williamstown, MA, in 1973, the M.A. degree in electrical sciences from Cambridge University, Cambridge, U.K., in 1975, and the Ph.D. degree in electrical engineering from the University of California at Berkeley, in 1980.

$\mathrm{He}$ is currently Professor of Electrical Engineering, Executive Officer for Electrical Engineering, and Director of the Lee Center for Advanced Networking at the California Institute of Technology, Pasadena. He has authored the electronics textbook, Electronics of Radio (Cambridge, U.K.: Cambridge Univ. Press, 1999), and co-authored the popular microwave computer-aided design software package "Puff," which has sold over 20000 copies.

Dr. Rutledge was the recipient of the 1995 IEEE Microwave Theory and Techniques Society (MTT-S) Microwave Prize and the 1997 Distinguished Educator Award presented by the IEEE MTT-S. Five of his former students have been the recipients of Presidential Investigator Awards presented by the National Science Foundation. 